\title{
O ADOLESCENTE, O FÃ E A ESCOLA: REFLEXÕES SOBRE AS (IM) POSSIBILIDADES DO DESEJO NO ATO EDUCATIVO
}

\author{
Daniela de Souza Silva ${ }^{1}$ \\ https://orcid.org/0000-0003-4228-6097 \\ Inês Maria Marques Zanforlin Pires de Almeida² \\ https://orcid.org/0000-0002-1292-7327
}

RESUMO: O presente artigo resulta de um desdobramento de uma dissertação de mestrado, onde se buscou refletir acerca da constituição subjetiva da adolescência atravessada pela cultura de fãs, configurada como fenômeno da cultura digital por meio das fandoms e das fanfics, num processo de socialização e criação de histórias, movidas por um interesse mútuo, invejável à cultura escolar. Para esse alcance, foi feito um percurso investigativo por meio da psicanálise, que foi tomada como ótica sobre o estudo da subjetividade, e a bricolagem como estudo da complexidade, em que diferentes saberes e experiências são reunidos em torno do fenômeno das fanfics. A aposta deste estudo foi por uma compreensão sobre o ressoar desse fenômeno na vida psíquica dos adolescentes que o constituem, em que medida o inconsciente opera nas narrativas fictícias criadas por esse público e de que maneira esse exercício narrativo revela sentidos para a experiência da escola. Aqui, fomos interrogados sobre as implicações do desejo no ato educativo e sobre as (im)possibilidades de um sujeito adolescente fã insurgir como estudante.

PALAVRAS-CHAVE: Adolescência. Fanfic. Psicanálise. Escola. Ato educativo.

\section{THE ADOLESCENT, THE FAN AND THE SCHOOL: REFLECTIONS ON THE (IM) POSSIBILITIES OF DESIRE IN EDUCATION}

ABSTRACT: This article is an unfolding of a master's dissertation, where we sought to reflect on the subjective constitution of adolescence crossed by the culture of fans, configured as a phenomenon of digital culture through fandoms and fanfics, in a process of socialization and creation of stories, driven by a mutual interest, enviable to school culture. To achieve this, an investigative path was made through psychoanalysis, which was taken as an optics on the study of subjectivity, and bricolage as a study of complexity, in which different knowledge and experiences are brought together around

1 Mestre em Educação pela Universidade de Brasília. Orientadora Educacional da Secretaria de Estado de Educação do DF. Brasília-DF, Brasil. danidanidesouza@gmail.com

2 Doutora pelo Instituto de Psicologia da Universidade de Brasília. Pesquisadora Colaboradora do Programa de Pós-Graduação da Faculdade de Educação da Universidade de Brasília. Brasília-DF, Brasil. almeida@unb.br 
the phenomenon of fanfics. The focus of this study was on an understanding of the resonance of this phenomenon in the psychic life of the adolescents that constitute it, the extent to which the unconscious operates in the fictional narratives created by this audience and how this narrative exercise reveals meanings for the school experience. Here, we were asked about the implications of desire in the educational act and the (im) possibilities of an adolescent fan subject to rise as a student.

KEYWORDS: Adolescence. Fanfic. Psychoanalysis. School. Education act.

\section{EL ADOLESCENTE, EL FAN Y LA ESCUELA: REFLEXIONES SOBRE LAS (IM) POSIBILIDADES DEL DESEO EN LA EDUCACIÓN}

RESUMEN: Este artículo es un despliegue de una tesis de maestría, donde se buscó reflexionar sobre la constitución subjetiva de la adolescencia atravesada por la cultura de los fans, configurada como un fenómeno de la cultura digital a través de fandoms y fanfics, en un proceso de socialización y creación de historias, impulsado por un interés mutuo, envidiable a la cultura escolar. Para lograrlo, se realizó un recorrido investigativo a través del psicoanálisis, que se tomó como óptica sobre el estudio de la subjetividad, y el bricolaje como estudio de la complejidad, en el que se conjugan diferentes saberes y experiencias en torno al fenómeno de los fanfics. El enfoque de este estudio fue comprender la resonancia de este fenómeno en la vida psíquica de los adolescentes que lo constituyen, la medida en que el inconsciente opera en las narrativas de ficción creadas por esta audiencia y cómo este ejercicio narrativo revela significados para la experiencia escolar. Aquí, nos preguntamos sobre las implicaciones del deseo en el acto educativo y las (im) posibilidades de un sujeto adolescente aficionado de ascender como estudiante.

PALABRAS CLAVE: Adolescencia. Fanfic. Psicoanálisis. Escuela. Acto educativo.

\section{Breves considerações sobre a adolescência e psicanálise}

Antes de adentrarmos o universo dos fãs que se constituem nas fanfics, traçaremos algumas considerações sobre o adolescente, sujeito dessa investigação, e suas relações com a psicanálise.

Apesar de nunca se referir à "adolescência", Freud registrou em seus estudos as mudanças ocorridas na psiquê humana naquilo que chamou de "transformações da puberdade". Em "Três ensaios sobre a teoria da sexualidade", Freud (1905/1997) afirma que a puberdade é um verdadeiro momento de metamorfose da subjetividade. Antes de adentrarmos essa esfera de transição, 
precisamos relembrar a importante e polêmica teoria sobre a sexualidade infantil assinalada por Freud. Numa época em que parecia inconcebível não apenas adentrar as questões mais íntimas e consideradas "tabu" pela 27 sociedade vitoriana, com suas tradições e puritanismo moral, a psicanálise vem romper um paradigma sobre a infância e a inocência imaculada das crianças, ao alegar que todos os sujeitos, desde a mais tenra idade, já possuem sexualidade e se constituem por meio de pulsões sexuais. Aquilo que até então parecia somente irromper nos seres humanos ao alcançarem uma determinada maturação, evidenciada a partir da puberdade, na verdade, conforme assinalado por Freud, já era constituinte dos sujeitos desde o momento de seu nascimento.

No entanto, a sexualidade infantil possui suas especificidades, dentro de um

processo que Freud concebe como predominantemente autoerótico, ou seja, os prazeres e satisfações experimentados pelo bebê e pela criança são de uma ordem muito mais independente e autoexploratória, enquanto nos adultos eles tornam-se mais voltados para alvos externos e, portanto, são mais dependentes do outro para encontrar prazer e satisfação. Há também um importante processo psíquico muito trabalhado por Freud que se inicia na infância e atravessa, direta ou indiretamente, as demais fases da vida, denominado "Complexo de Édipo". Esse conceito refere-se ao período em que a criança, seja menino ou menina, demonstra seus primeiros traços de amor a seus pais, ou referências parentais, por receber deles afeto. Via de regra, o menino demonstra ter desejos intensos de amor por sua mãe, concluindo, por fim, ser o pai seu rival; a menina, em primeira instância, também demonstra ter desejos intensos de amor por sua mãe, mas, realizando a troca de seu "objeto original", demonstra ter desejos intensos de amor por seu pai (FREUD, 1931/1996).

Lacan (1995) releu a teoria freudiana, explicando então o Édipo em três tempos. Inicialmente, quando a criança ainda é muito pequena e dependente da mãe, ela a enxerga como um espelho e extensão do próprio corpo e se reconhece como o único objeto de desejo dela, numa espécie de fantasia incestuosa. No segundo tempo, o pai se torna presente como uma figura proibidora, aquele que interdita o desejo da criança pela mãe. Ele atua como uma autoridade que impõe regras e limites, indicando à criança o seu lugar na relação familiar. Essa figura paterna culturalmente construída, passa a ser introjetada desde cedo com um signo da Lei que se inscreve nos sujeitos. 0 terceiro tempo se refere ao momento em que a criança passa a perceber a mãe como um objeto de desejo impossível, dado que é interditado pelo pai, 
o que a mobilizará em busca de outros objetos de desejo fora daquela relação parental. Nesse contexto, o pai aparece como uma figura de identificação, em que passa a ser visto como um homem cotidiano, com 28 seus defeitos e qualidades, sem os velhos traços de idealização ou rivalidade. Essa configuração marca o lugar ambivalente do sujeito (ego) para sempre dividido entre o desejo (id) e a Lei (superego).

Esse seria o caminhar esperado de uma constituição psíquica tida como "normal", em que o complexo edípico se dissolve.

Todas as relações que desenvolveremos ao longo da vida sofrerão influência dessa experiência primária vivida com os pais, sendo, portanto, todos os laços sociais e afetivos carregados de ambivalência. Para Freud, todas as pessoas a quem somos ligados em nossa socialização são figuras substitutivas das pessoas com as quais nos relacionamos em nossas mais tenras idades, isto é, nossos pais.

\begin{abstract}
[...] Relacionamentos posteriores são assim obrigados a arcar com uma espécie de herança emocional, defronta-se com simpatias e antipatias para cuja produção esses próprios relacionamentos pouco contribuíram. Todas as escolhas posteriores de amizade e amor seguem a base das lembranças deixadas por esses primeiros protótipos (FREUD, 1914/1996, p. 257).
\end{abstract}

A relação que estabelecemos com o nosso desejo e com as regras e autoridade estabelecidas também serão marcadas por essas experiências iniciais.

A adolescência carrega, assim, as marcas das experiências introjetadas da sexualidade infantil e da estrutura edípica formada na relação com os pais. 0 que ocorre nesse processo de transição da infância para a puberdade é, portanto, uma espécie de (re)abertura da sexualidade que se encontrava internalizada e de busca de uma nova identidade, que passam a (re)constituir-se e expressar-se no mundo externo, no Outro.

Esse caminho, no entanto, mostra-se bastante complexo, uma vez que serão despertadas uma série de impressões psíquicas experimentadas na infância que, muitas vezes, não encontraram um lugar na consciência e foram esquecidas ou, então, sofreram um impedimento ou bloqueio que deram origem aos emblemáticos "recalques".

Esse tipo de reavivamento psíquico iniciado na puberdade é o principal gerador, para Freud, das frequentes tensões e conflitos experimentados pelos adolescentes. Como se uma espécie de ebulição sexual aliada ao desejo imperativo de reconstrução da própria imagem tomasse conta da vida psíquica, 
mas sem nunca encontrar um caminho fácil de confluição, considerando que, tanto os limites da experiência infantil irão resvalar ao longo da puberdade e, mais tarde, na vida adulta, como os limites da cultura irão se circunscrever na ação dos sujeitos no mundo. Lacan (1998) revê a complexidade da adolescência como a elaboração do luto dos pais da infância, do corpo infantil e o real do sexo.

Os traços de rebeldia, tão comuns na adolescência, são, nessa leitura, uma consequência do processo de superação dos pais e da 29 própria infância, uma forma de simbolizar o luto pela etapa que fica para trás e uma busca por uma nova identidade, uma reedição do próprio narcisismo. A noção do "eu" infantil, que parecia completo, entra em conflito com essa imagem de si mesmo e a saída possível será uma tentativa de superar essa impossibilidade na forma de um Ideal de Eu (FREUD, 1914/1996).

Os fantasmas da infância acompanham o adolescente, mas também o engajam novos lugares de palavras, de objetos e de outros. $O$ adolescente busca novos significantes (RASSIAL, 1999).

O período da adolescência seria, na perspectiva psicanalítica, um trânsito complexo e exigente do sujeito da infância para o sujeito da vida adulta, ou seja, é quando é invocada a saída de um sujeito autocentrado, cujas necessidades e desejos orbitavam em torno de si mesmo, para um sujeito voltado para o outro, para o mundo, cujas necessidades e desejos passam a ser dirigidas para um alvo externo.

A sexualidade e o desejo, combustíveis desse processo, passam a constituir-se numa permanente tensão causada pelas demandas externas, advindas dos outros sujeitos e sua relação com a cultura estabelecida, e as pulsões internas, que agora vêm à tona de forma mais intensa e elaborada, convocando o sujeito a ressignificar sua libido em seu ego não mais infantil.

São esperadas então as angústias, medos e o horror como sintomas do mal estar provocado pela dinâmica social do desprazer e da frustração do ego infantil, para o cumprimento de um papel num novo lugar, o de adulto (a ser) constituído dentro de um projeto civilizatório movido a regras e contradições.

As pulsões sexuais na adolescência tendem a reservar-se num espaço íntimo e muitas vezes, oculto, podendo, contudo, assumirem-se sob outras formas no mundo externo, como por meio de grandes ímpetos que surgem em torno de uma grande fonte de interesse, seja de natureza intelectual, artística, lúdica ou, até mesmo, alguma atividade transgressora, rebelde. Esse efeito de sublimação da sexualidade, por meio de diferentes "disfarces" ou "encobrimentos" criativos, tornam a adolescência uma época de grande potência fértil em diferentes aspectos da vida do adolescente. 


\section{A adolescência e a cultura de fãs}

O Dicionário Aurélio ${ }^{3}$ nos define fã como um indivíduo que admira entusiasticamente uma figura pública, geralmente do mundo do espetáculo. Pessoa que nutre grande admiração por alguém ou alguma coisa. Jenkins (1992) nos informa, por meio do Dicionário Oxford, que "fã" é uma forma abreviada da palavra "fanático", que tem suas raízes na palavra latina "fanaticus". Em seu sentido mais literal, "fanaticus" significa simplesmente "De ou pertencendo ao templo, um servo do templo, um devota", mas rapidamente assumiu conotações mais negativas, "de pessoas inspiradas por ritos de orgias e frenesi entusiástico." (JENKINS, 1992, p. 12).

Nessa leitura, o autor nos coloca que, historicamente, o termo "fanático" foi associado a formas excessivas e equivocadas de crenças religiosas ou políticas, que levavam as pessoas a agir de forma insana, como se estivessem numa espécie de "posse demoníaca". Porém, a forma abreviada "fã" apareceu pela primeira vez no final do século 19 nos Estados Unidos, em relatos jornalísticos descrevendo seguidores de equipes esportivas profissionais (especialmente no beisebol), num momento de popularização dos espectadores.

Também, um de seus primeiros usos foi em referência às mulheres frequentadoras de teatro, chamadas de "garotas da matinê", cujos críticos do sexo masculino alegavam que sua assiduidade se dava muito mais em torno da admiração pelos atores, do que pelas peças em si (JENKINS, 1992). A ambiguidade entre fanatismo e admiração, para Jenkins, caminham juntas desde então, e ainda se mostram presentes em muitas das representações de fãs no discurso contemporâneo.

O que melhor caracteriza o estudo de Jenkins é sua percepção positivamente diferenciada sobre os fãs. Enquanto muitos associam esse tipo de espectador a um consumidor passivo e acrítico de um produto cultural, ele percebe que os fãs constituem uma comunidade particularmente ativa e expressiva de consumidores cujas atividades direcionam a atenção para um processo de apropriação cultural. A vigorosa admiração que os fãs desenvolvem em torno de um objeto artístico ou cultural é capaz de promover um aprofundamento e uma criticidade mais aguçada sobre estes, do que no restante do público em geral, devido à intensidade de seu interesse.

Essa mobilização em torno de um importante objeto de interesse acaba levando, muitas vezes, os fãs a um processo recriação artística, por exemplo, quando buscam reescrever uma obra literária ou um roteiro de cine-

3 (https://dicionariodoaurelio.com/fa)

Rev. Fac. Educ. (Univ. do Estado de Mato Grosso), Vol. 35, Ano 20, № 1, p. 135-152, jan./jun, 2021 (Epub Ahead of Print 31 maio, 2021). 
ma, destacando personagens ou cenários, cruzando-os com outras histórias, enfim, interagindo e alterando sua fonte original a seu bel prazer e imaginação.

Não intimidados pelas concepções tradicionais de propriedade literária e intelectual, os fãs atacam a cultura de massa, reivindicando seus materiais para uso próprio, retrabalhando-os como base para suas próprias criações culturais e interações sociais. Fãs aparentemente ofuscam as fronteiras entre fato e ficção, falando de personagens como se tivessem uma existência à parte de suas manifestações textuais, entrando no reino da ficção como se fosse um lugar tangível que eles possam habitar e explorar. (JENKINS, 1992, p. 26)

O autor inicia seus estudos sobre a cultura de fãs a partir da observação de comunidades nos Estados Unidos formada por telespectadores assíduos de séries de TV, como Twin Peaks e Star Trek, que se reuniam periodicamente para trocar ideias, reviver as histórias e, inclusive, reescrevê-las. Esse exercício dos fãs revelava não apenas um sentido de coletividade suscitado pelo interesse em comum, mas também um processo ao qual Jenkins se referiu como "cultura participativa". A potência dos fãs passa a ser vista não apenas como na recriação de histórias, mas também na transgressão autoral e comercial, já que representam um grupo "ilegítimo" de autores e artistas.

Certeau (1994) teve parte nessa visão adotada por Jenkins, quando escreveu sobre a recepção ativa dos leitores quando do contato com uma obra literária, referindo-se a eles como "viajantes": “(...)eles se movem por terras pertencentes a outra pessoa, como nômades se arrastando por campos que não escreveram, roubando a riqueza do Egito para se divertirem" (CERTEAU, 1994, p. 174). A circulação de significantes entre o olhar do leitor e a obra em si, dão à leitura um caráter majoritariamente interpretativo, multifacetado, uma vez que resvala inevitavelmente na subjetividade de seu receptor.

A diferença entre o leitor comum e o fã está um passo à frente, pois o fã geralmente materializa a sua recepção por meio da exposição aos demais adeptos. Ao buscar compartilhar sua fonte de interesse com outros iguais, cria-se um status de grupo que passa a ser entendido como fandom, que seria uma espécie "domínio dos fãs" (ou fã-clubes, como os conhecemos no Brasil), que "sinaliza uma declaração de afeição mais ampla e compartilhada" (MORRISSEY, 2016, p. 353). E continua: "Quando pesquisadores estudam fandoms, eles frequentemente querem saber como os fãs estão se envolvendo com a mídia e dando sentido à cultura popular" (MORRISSEY, 2016, p. 353). 
Com o advento da internet e integração da cultura digital, os fandoms passaram a constituir-se principalmente por meio de fóruns e plataformas virtuais, onde os fãs discutem e exploram suas histórias e artistas preferidos, tornando-se ricos espaços também de criação e expansão de universos ficcionais, de onde podem extrair elementos para escrever suas histórias, dando origem às fanfics. As histórias de fanfics são obras literárias que tomam emprestadas as configurações, enredos, personagens e ideias de todas as formas de cultura popular, na tentativa de tecer novas histórias que se baseiam em histórias existentes em todos estilos e formas (LEE, 2011).

Mas como a adolescência se inscreve na cultura de fãs? O que sabemos, pela perspectiva psicanalítica, é que a adolescência, enquanto uma fase subjetiva, implica fortemente num processo busca dos sujeitos por objetos externos, com os quais possam se identificar e sublimar seus desejos mais íntimos. A necessidade imperativa de rompimento com a vida infantil e com a dependência familiar, torna-os mais propensos às paixões ou fantasias temporárias de serem acometidos por agentes externos que os arranquem daquela condição. Como se ensaiassem sua saída da infância por meio da imaginação, da simbolização de seus anseios em objetos de desejo inacessíveis ou intocáveis, como artistas ou obras de ficção, com os quais podem sonhar, mas também manterem-se protegidos em sua vida material.

Assim, enveredar-se como fã torna-se um caminho recorrente na adolescência, na medida em que está estabelecida a abertura para as conexões emocionais com objetos fictícios. A reunião de adolescentes em torno de um objeto de interesse comum leva-os, mais frequentemente, a constituírem os tais fã-clubes, ou fandoms, demonstrando ser essa uma configuração favorável aos processos de identificação e sublimação que urgem nessa fase da vida, conceitos que Freud (1921/2011) nos apresentou em Psicologia das Massas e Análise do Eu. A identificação é tida como a mais remota expressão de um laço emocional com outra pessoa, um interesse especial que demonstramos desde a mais tenra infância, que conflui com uma busca, um ideal, um desejo de ser ou agir como um outro.

Os adolescentes identificados e reunidos em torno das fanfics, representam um potencial emergente do fenômeno dos grupos psicológicos, que é o da realização coletiva em prol de um ideal compartilhado. E é na arte que encontram essa possibilidade de sublimação, por sua capacidade de retirar exatamente da frustração e do desejo a tensão para alcançar as culminâncias do percurso criativo (ALETTI, 2004). E essa realização, por meio das histórias produzidas, busca reconstituir nos sujeitos uma experiência de bem-estar 
que o amor, a religião e a arte procuram, de certa maneira, reconstituir, numa experiência vivida na qual a realidade interna e a realidade externa não são percebidas como separadas.

Para Freud, o artista se diferencia do neurótico porque consegue escapar da realidade insatisfatória por meio de suas realizações criativas, mas sem abandonar totalmente a realidade, apenas fazendo da arte uma espécie de lar temporário. Suas criações, obras de arte, são as satisfações imaginárias de desejos inconscientes (FREUD, 1925/1996).

Podemos dizer que os adolescentes, ao produzirem suas histórias no ciberespaço, acessam outra realidade psíquica, a da fantasia, e afastam-se, durante esse processo, das insatisfações advindas da realidade material. Mas o percurso da sublimação através da arte não é somente o do distanciamento temporário da realidade, pois o ato criativo também permite uma reinvenção: através da arte pode-se ressignificar vivências, encontrar saídas significativamente distintas, novas, estranhas, desconhecidas frente às perguntas enunciadas, menos dirigidas às constatações do já sabido acomodado em respostas conhecidas (DERDYK, 2001).

É que a noção de sublimação, para a psicanálise, acarreta não apenas num ponto de fuga, mas também em um reposicionamento do sujeito diante da realidade. Ela representa uma tentativa, segundo Freud, de transformação e ultrapassagem de algo baixo em direção ao que é socialmente idealizado; ou, como releu Lacan posteriormente, "o sublime é o ponto mais elevado do que está embaixo." (LACAN, 1985, p. 18).

E foi exatamente 0 apreço de Freud e Lacan pelas artes que tornou a psicanálise tão estreita ao ato artístico, pois observaram que tanto o autor quanto o espectador de arte são implicados numa obra de forma inconsciente, sendo por ela provocados não apenas com prazer e conforto, mas também com espanto e incômodo. Ainda que, para Freud, autor e espectador ocupem lugares diferentes na arte: "O artista se atém aos mínimos detalhes de sua realização, pois ela é uma representação simbólica daquilo que existe em seu âmago, logo ela precisa fazer jus ao que serviu para inspirá-la" (COSTA, 2017, p. 15). Nesse ponto, o artista nunca está plenamente satisfeito com sua realização, enquanto para um espectador pode tratar-se de uma obra-prima.

Mas aquilo que se encontra no âmago da sublimação, que é de ordem inconsciente, é sempre uma pulsão, uma força libidinal, que não encontra um caminho fácil ou possível no mundo externo. Assim, o ato artístico representa para a pulsão um destino criativo, uma possibilidade de reinventar-se por meio de fantasias numa realidade imaginária. 
As ficções produzidas pelos adolescentes são, portanto, sujeitas a uma ação de sublimação, no qual se torna possível revelar desejos, sonhos e inibições que não têm lugar em sua realidade material.

Essa dimensão do fenômeno nos permite compreender melhor a expressividade de conteúdos românticos, eróticos e fantásticos, por exemplo, que comparecem de forma recorrente nas fanfics. A plataforma de publicação dessas ficções acaba funcionando como uma espécie de realidade alternativa, onde os recalques podem se transformar em enredos.

\section{A adolescência e a escola}

Para traçarmos a relações da adolescência e escola, iremos transitar rapidamente pelas contribuições da psicanálise sobre a vida em sociedade e o projeto social no qual a educação ocupa.

Em seu texto "O mal estar na civilização", Freud (1929/1996) problematiza a incessante busca do homem pela felicidade, enunciando um conflito inerente à nossa condição de vida em sociedade: sempre haverá um embate intransponível entre as pulsões internas e as exigências da civilização. Para vivermos juntos, num projeto maior que nossa própria esfera pessoal, precisamos sacrificar nossa libido, aqui entendida como uma energia vital, propulsora das pulsões. Sem lugar para a satisfação pessoal, o homem sacrificado encontra o mal estar em sua cultura e dele torna-se refém. As relações pesam entre os homens quando não há espaço para a emergência das singularidades, dos desejos. O mal estar na civilização é representado, assim, pelo mal estar nos laços sociais.

Na escola, esse mal estar fica evidente quando professores, direção e pedagogos não sabem o que fazer para lidar com aqueles que não se encaixam na norma geral apresentada nas suas propostas pedagógicas (SOUZA, 2007). A escola que conhecemos reveste-se dos moldes civilizatórios que exigem dos sujeitos um sacrifício permanente de sua singularidade. Sem espaço para "ser" ou "desejar", o sujeito investido no papel de estudante abandona-se de si mesmo para atender às demandas da instituição escolar.

Millot (1990), em seu emblemático livro "Freud Antipedagogo", analisou as críticas de Freud à educação (que nunca chegou a dedicar-se com afinco a este tema, mas deixou em suspenso algumas reflexões que vieram a ser mais fortemente exploradas pelos estudiosos de psicanálise e educação) e nos alertou para a impossibilidade de transpor o antagonismo existente entre a educação e a moral sexual civilizatória e a manifestação das tendências 
pulsionais de cada sujeito. Como resultado desse conflito, resta aos sujeitos extravasar essas energias por via colaterais, nem sempre saudáveis, e que podem levar a uma satisfação neurótica ou perversa de suas pulsões.

Tanto os pais quanto os professores, investidos num projeto educativo pertinente às demandas sociais, não conseguem propiciar um espaço ou tempo que atenda às demandas da vida íntima das crianças e dos adolescentes. Sendo majoritariamente proibitiva e coercitiva, a educação dos adultos torna-se avessa à própria psicanálise, que nasce investida na tarefa de dar voz e lugar ao sujeito do inconsciente, com seus sonhos e desejos reprimidos.

De Lajonquière (1999), dedicado ao estudo da psicanálise e da educação, realiza uma leitura, a partir da utilização de conceitos psicanalíticos, do sintoma social que nomeia como discurso (psico)pedagógico hegemônico, que é sustentado por uma ilusão e que desvirtua tão gravemente a educação, sendo o responsável pelo fracasso da mesma nos dias de hoje. Sua crítica recai nas concepções maturacionais do desenvolvimento humano nas quais se apoia a pedagogia moderna, tendo a ilusão de poder controlar o processo educativo. Cada ato realizado por um adulto é pensado nesses termos, recorrendo a manuais de instrução de "como funciona". Desta forma, a criança e o adolescente ocupam um lugar de objeto desse discurso, perdendo a possibilidade de vir a se constituírem como sujeitos de um desejo.

Assim, a relação entre o desejo e a educação parecem constituir-se como dicotômicas, e o lugar do adolescente na culturaa de fãs deixa esse aspecto ainda mais evidenciado.

Nakagome e Murakami (2013) observam que a cultura de fãs reflete uma paixão e uma criatividade em torno de uma obra ou um artista invejáveis à cultura escolar que, frequentemente, se vê às voltas com o desinteresse dos estudantes pela literatura, por exemplo. Na percepção das autoras, os fãs representam um modelo de leitor conhecedor e autônomo que desejamos formar em nossas escolas.

Contudo, sabemos que são muitas variáveis que influenciam o (des) andar da escola, e a psicanálise nos tem ajudado a pensar nos espaços e lugares que parecem instransponíveis entre os sujeitos e as instituições, que resvalam também nas relações entre alunos e professores e que resultam na dificuldade da constituição de laços sociais.

Calligaris (2000) defende ser inevitável uma insatisfação e inquietação dos adolescentes em nossa sociedade, pois "numa cultura individualista como a nossa, espera-se de antemão que qualquer sujeito se construa um lugar e se invente um destino contra o que a tradição e o berço onde nasceu lhe re- 
servam". (CALLIGARIS, 2000, p. 63). Situação que se relaciona a uma diluição dos ritos de passagem ao longo do tempo. De acordo com Manoni (2004) a única forma de passagem que é oferecida hoje aos jovens é o "modelo escolar". Porém, algo grave acontece aí, pois eles não sabem em que são iniciados.

Em uma resposta que redige sobre o elevado número de suicídios de estudantes secundaristas na sua época, Freud (1910/1996) coloca que a escola deve oferecer aos alunos apoio e amparo, pois esse é o momento em que os adolescentes "afrouxam" seus vínculos com a família para se interessarem por outros ambientes na vida. No mesmo ensaio, Freud alega que os adolescentes são indivíduos imaturos e que a escola deve acolhê-los, mesmos nos seus aspectos mais desagradáveis (FREUD, 1910/1996, p. 217). Em outros ensaios, Freud acentua a importância da escola e dos educadores para a formação do sujeito, quando utiliza exemplos de sua própria experiência de vida para afirmar que o ambiente escolar, seja pela presença dos colegas, seja pela presença dos professores, teve influência significativa sobre suas escolhas, sua carreira e seu pensamento. (OLIMPIO e MARCOS, 2015).

Freud então nos presenteou com uma reflexão que balizou o pensamento sobre a educação e psicanálise: "É difícil dizer o que exerceu mais influência sobre nós e teve importância maior foi a nossa preocupação pelas ciências que nos eram ensinadas, ou pela personalidade de nossos mestres (...) para muitos, os caminhos das ciências passavam apenas através de nossos professores". (FREUD, 1914/1996, p. 248).

No "Prefácio à juventude desorientada", de Aichhorn, Freud (1925/1980) destaca que a educação tem como objetivo "orientar e assistir as crianças em seu caminho para diante e protegê-las de se extraviarem" (FREUD, 1925/1980, p. 307). Nesse ensaio, ele deixa claro que a tarefa da escola é educar inibindo, proibindo e coibindo, mas desde que com moderação. Acrescenta ainda que se deve levar em consideração a diferença entre as crianças, de forma que não se deve padronizar o método educativo. Ele ainda sugere que, para o melhor desempenho da sua função, os educadores devem conhecer a psicanálise e encoraja-os a submeterem-se a ela para compreenderem melhor a si e aos seus alunos. (OLIMPIO e MARCOS, 2015).

As reflexões de Freud acerca do papel da educação, e da psicanálise como possibilidade de amparo a essa função social, nos levam a pensar sobre "como" fazer isso, melhor, sobre como se daria essa relação entre educação e psicanálise à serviço do professor e seu aluno adolescente. 


\section{A transferência no ato educativo}

O sujeito adolescente, atravessado pelas metamorfoses de puberdade, em que se vê às voltas com a desconstrução da infância e dependência familiar, tende a buscar na escola um lugar de transferência de autoridade e afeto, onde poderá amparar-se com segurança para, então, ganhar autonomia e ressignificar sua própria identidade. Esse processo acarreta, inevitavelmente, na transferência das referências parentais dirigidas à figura do professor, que passa a ser investido de uma importância especial. Claro que, as experiências anteriores dos alunos irão influenciar positivamente ou negativamente essa transferência, que aparecerá como uma reedição dos afetos passados.

Para Kupfer (1989), na transferência, a figura do professor é esvaziada de sentido e preenchida pelo aluno conforme sua fantasia. Transferir é "atribuir um sentido especial àquela figura determinada pelo desejo". (KUPFER, 1989, p. 92). Se o desejo do aluno transfere determinado sentido ao professor, conhecer esse sentido é quase impossível. A autora nos lembra que o professor pode ter no máximo alguns flashes desse desejo e, mesmo assim, se for bastante atento à singularidade desse aluno de modo que possa perceber o sentido atribuído a partir do desejo inconsciente.

Na perspectiva psicanalítica, o professor deveria, portanto, renunciar a essa posição de sujeito detentor do saber, que Freud chamou de Ideal do Eu. Esse lugar poderoso, de um sujeito que detém o saber, é dado ao professor pelo aluno. Renunciando a esse lugar, o professor contribui para que o aluno lide com a frustração de não corresponder às suas próprias expectativas e com isso abra uma importante porta para livrá-lo de seu passado infantil. É como se o professor passasse a sair de cena dando condição ao aluno de caminhar de forma um pouco mais autônoma, o que é fundamental para se constituir como sujeito. No entanto, a tendência é o professor fazer uso do lugar de poder que lhe é conferido para impor ao aluno suas ideias e valores, ou seja, impor o próprio desejo. (SANTOS, 2009)

Caso o professor caia nessa armadilha de seu próprio narcisismo, acabará castrando o poder desejante de seu aluno, pois ao se exibir como detentor do saber absoluto, o professor se coloca como um ser completo, possuidor daquilo que falta ao aluno e que pode completá-lo (e a completude é sempre uma ilusão). A tarefa do professor se resumirá, assim, de acordo com Kupfer (1989) a contribuir para a formação de um ideal que tem uma função meramente reguladora.

Nesse caso, o aluno poderá tanto se tornar um mero reprodutor dos conteúdos passados pelo professor, sem nunca atingir, de fato uma autonomia; 
como poderá simplesmente aborrecer-se ou desinteressar-se, não se inscrevendo, portanto, como educando. Ambas consequências refletem igualmente a falta de um lugar para a emergência das singularidades do aluno, por darem somente espaço para a padronização do ato educativo.

Mas é importante lembrar que esses processos costumam ocorrer tanto no professor quanto no aluno de forma inconsciente, dificultando, assim, sua compreensão e possíveis saídas. Tende-se, usualmente, a focar especialmente em métodos e técnicas como respostas aos impasses pedagógicos, desconsiderando, muitas vezes, os processos subjetivos nos quais os sujeitos professor e aluno estão investidos.

Kupfer (1989) nos diz que, para o professor trabalhar em prol do sujeito, ele deve renunciar também a outros ideais, tal como a preocupação excessiva com métodos de ensino ou com a didática padronizada, além de abandonar as técnicas de adestramento, as recompensas e premiações. Também é fundamental procurar reduzir a homogeneização presente no ambiente escolar, justamente por entender que cada sujeito detém sua singularidade e transfere ao professor representações e sentidos diversos. (RIBEIRO, 2014).

O problema na didatização excessiva da escola, é que ela reflete também uma tendência massificante da sociedade, na qual os discursos capitalistas e científicos se inscrevem e que resultam no apagamento das exceções e dos laços, a coisificação do sujeito e a segregação. Com base em Lacan, Olimpo e Marcos (2015) entendem que a escola precisa acolher as diferenças ao mesmo tempo em que dá voz às individualidades: “Na escola, o sujeito deverá se sentir incluído, mas também separado. O posicionamento do sujeito no mundo frente à dualidade (fazer parte do Todo e ser Um) tem sido dificultada por parte da sociedade atual que não agrega." (OLIMPIO e MARCOS, 2015, p. 504).

Isso não significa, contudo, que a psicanálise seja favorável à liberdade total e ausência de limites, em prol do desejo. Sabemos, desde Freud, que o domínio das pulsões são imprescindíveis para a adaptação da vida em sociedade, portanto, ao exercer sua autoridade, o professor também ajuda o aluno a inscrever-se num mundo que é composto por regras sociais. O que a psicanálise nos lembra a todo tempo é que a autoridade do professor não deve anular as singularidades dos alunos, mas dar um lugar para elas, dentro dos limites estabelecidos pela cultura. Assim, sempre haverá um nível de frustração no ato educativo, seja pela aceitação da falibilidade do professor, seja pela impossibilidade de estar sempre em dia com o próprio desejo. Mas, também, um desafio e um aprendizado na superação do narcisismo e na possibilidade constituição de laços sociais dentro do espaço escolar. 
A compreensão sobre os processos inconscientes proposta inicialmente por Freud e relida pelos estudos em educação e psicanálise, indicam, mas não prescrevem, possibilidades aos professores diante da complexidade do ato educativo. Olhar a si mesmo e, então, olhar o outro-adolescente, implica em perceber-se, a todo tempo, como um sujeito também dividido.

Entre o adolescente do passado, aquele que um dia o educador já foi e o adolescente real, de carne, ossos e desejos, estende-se uma diferença radical. Da mesma forma, existe uma diferença entre a imagem ideal do mestre que corresponderia àquela que seria capaz de educar sem perdas e danos e o adulto concreto, incapaz de atender às exigências de perfeição que essa imagem Ihe impõe. (OLIMPIO e MARCOS, 2015, p. 509).

Ao olhar-se como o adolescente que já foi, o professor diminui as distâncias na relação com o aluno e então pode implicar-se com ele. Esse processo permitirá, por exemplo, o estabelecimento de um diálogo com as experiências vivenciadas hoje pelos adolescentes tanto no mundo físico como virtual, nos quais eles facilmente transitam e de onde retiram seus valores, seus gostos, sua visão sobre o mundo e, por que não, suas próprias regras.

Esse tipo de "empatia" despertada no outro, e que favorece a constituição de laços, é condição fundamental para tudo mais que se espera da educação, e sem a qual não mais opera significativamente.

O "desejo de aprender" surge nesse contexto como uma consequência da relação estabelecida entre professor e aluno, e não como uma causa, um fato inicial que, por si só, garante o aprendizado.

\section{Implicações do fã e do estudante: o que há de se considerar?}

Ao retomarmos a questão trazida por Nakagome e Murakami (2013) acerca do fã como um modelo desejável de aluno, pensamos que, talvez, a escola não seja o melhor lugar para a emergência dos desejos, tendo em vista que estes requerem um relativo grau de liberdade para o exercício de sublimação, que destoa fortemente da função institucional. Entretanto, se a escola conseguir abrir mão do imperativo didático e de uma tradição distanciada dos interesses genuínos dos sujeitos que ali comparecem como alunos, ela terá mais chances de despertar o desejo pelo conhecimento, seja na forma da literatura, da matemática ou de tantas outras disciplinas com as quais eles se vêm às voltas na longa trajetória educacional. 
As autoras consideram que, no caso da literatura, seja fundamental que haja um espaço para aquelas obras lidas por uma "necessidade do coração, não da mente voltada ao cumprimento do programa semestral." (NAKAGOME e MURAKAMI, 2013, p. 81).

Acrescentamos a isso não apenas a flexibilidade na escolha do material (que por si só já enriquece a aula por considerar o fator afetivo como um combustível à leitura), mas também a implicação do professor tanto na relação com o objeto (no caso, a literatura) como na relação com as subjetividades que emergem a partir daquele objeto.

Afinal, nos perguntamos, será possível ao professor transformar seus alunos em fãs, sem ele ao menos inscrever-se como tal em seu próprio ato educativo?

\section{Referências}

ALETTI, M. A figura da ilusão na literatura psicanalítica da religião. Psicologia USP, São Paulo , v. 15, p. 163-190, 2004.

CALLIGARIS, C. A adolescência. Coleção Folha Explica. ed. São Paulo: PublifoIha, 2000.

CERTEAU, M. D. A invenção do cotidiano - Artes de fazer. Petrópolis: Editora Vozes, 1994.

COSTA, A. C. D. R. Entre ver e olhar: a arte pelos olhos da psicanálise, ljuí, n. Unijuí - Universidade Regional do Noroeste do Estado do Rio Grande do Sul, 2017.

DERDYK, E. Ponto de chegada, ponto de partida. In: A invenção da vida. Porto Alegre: Artes e Ofícios, 2001.

FREUD, S. Um caso de histeria, Três ensaios sobre a teoria da sexualidade e outros trabalhos. Edição Standard Brasileira das Obras Psicológicas Completas de Sigmund Freud. ed. Rio de Janeiro: Imago, v. 8, 1905/1997.

FREUD, S. Contribuições para uma discussão acerca do suicídio. Edição Standard Brasileira das Obras Psicológicas Completas de Sigmund Freud. ed. Rio de Janeiro: [s.n.], v. 11, 1910/1996.

FREUD, S. Algumas reflexões sobre a Psicologia Escolar. Edição Standard Brasileira das Obras Psicológicas Completas de Sigmund Freud. ed. Rio de Janeiro: Imago, v. 13, 1914/1996. No mesmo ensaio, Freud (1914. Em:. Rio de Janeiro:Imago, vol XIII,1996.) 
FREUD, S. Sobre o narcisismo: uma introdução. Edição Standard Brasileira das Obras Psicológicas Completas de Sigmund Freud. ed. Rio de Janeiro: Imago, v. $14,1914 / 1996$.

FREUD, S. Psicologia das massas e análise do Eu e outros textos. Obras Completas. ed. São Paulo: Companhia das Letras, v. 15, 1921/2011.

FREUD, S. Prefácio à "Juventude Desorientada" de Aichhorn. Edição Standard Brasileira das Obras Psicológicas Completas de Sigmund Freud. ed. Rio de Janeiro: Imago, v. 19, 1925/1980.

FREUD, S. Um estudo autobiográfico, Inibições, sintomas e ansiedade, A questão da análise leiga e outros trabalhos. Edição Stardard Brasileira das Obras Psicológicas Completas de Sigmund Freud. ed. [S.I.]: Imago, v. 20, 1925/1996.

FREUD, S. O mal estar na civilização. Edição standard brasileira das obras psicológicas completas de Sigmund Freud. ed. Rio de Janeiro: Editora Imago, 1929/1996.

FREUD, S. Sexualidade feminina. Edição Standard Brasileira das Obras Psicológicas Completas de Sigmund Freud. ed. Rio de Janeiro: Imago, v. 21, 1931/1996.

JENKINS, H. Textual Poachers: Television Fans and Participatory Culture. New York: Routledge, Chapman and Hall, ink, 1992.

KUPFER, M. C. Freud e a educação - o mestre do impossível. São Paulo: Editora Scipione, 1989.

LACAN, J. O Seminário, livro 20: Mais, ainda. 1a. ed. Rio de Janeiro: Zahar, 1985.

LACAN, J. Seminário IV: O complexo de Édipo - A relação de objeto (19561957). Rio de Janeiro: Zahar, 1995.

LACAN, J. O estádio no espelho como formador da função do eu tal como nos revela a experiência psicanalítica. Lacan J. Escritos. Rio de Janeiro: Zahar, 1998.

LAJONQUIÈRE, L. D. Infância e ilusão (psico)pedagógica: escritos de psicanálise e educação. São Paulo: Vozes, 1999.

LEE, A. Time Travelling with fanfic writers: Understanding fan culture through repeated online interview. Journal of Audience \& Reception Studies, University of Pennsylvania, v. 8, Maio 2011. 
MANONI, O. A adolescência é analisável? In: saios sobre a adolescência. Salvador: Ágalma, 2004.

Mais tarde. é agora. En-

MILLOT, C. Freud Antipedagogo. 1a edição. ed. México: Editora Paidos, 1990.

MORRISSEY, K. E. Gender and fandom: from spectators to social audiences. New York: Routledge, 2016.

NAKAGOME, P. T.; MURAKAMI, R. Y. Transculturalidade, transformação: a relação dos fãs e dos estudantes com a literatura. Interdisciplinar, Itabaiana, v. 19, p. 71-86, Julho-Dezembro 2013.

OLIMPIO, E.; MARCOS, C. M. A escola e o adolescente hoje: considerações a partir da psicanálise. Psicologia em Revista, Belo Horizonte, v. 21, p. 498-512, Setembro 2015.

RASSIAL, J.-J. O sinthoma adolescente. Estilos da Clinica, São Paulo, v. 4, n. n.6, p. 89-93, Julho 1999.

RIBEIRO, M. D. P. Contribuição da psicanálise para a educação: a transferência na relação professor-aluno. Psicologia da educação, São Paulo, v. 39, p. 23-30, 2014.

SANTOS, J. M. S. A transferência no processo pedagógico: quando fenômenos subjetivos interferem na relação de ensino-aprendizagem. Dissertação de Mestrado, Programa de Pós-graduação em Educação Conhecimento e Inclusão Social, da Faculdade de Educação da Universidade Federal de Minas Gerais. ed. Belo Horizonte: UFMG, 2009.

SOUZA, R. T. D. Mal estar na escola: uma leitura psicanalítica. [S.I.]: Corpo freudiano do Rio de Janeiro, 2007.

Data de recebimento: 05.06 .2020

Data de aceite: 12.05.2021 